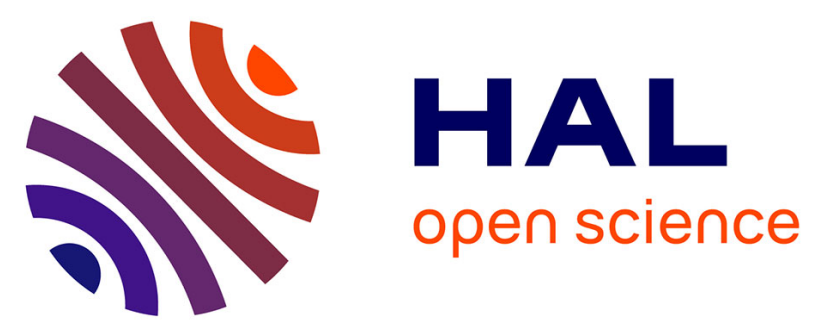

\title{
Usefulness of functional MRI associated with PET scan and evoked potentials in the evaluation of brain functions after severe brain injury: preliminary results.
}

Stéphane Kremer, Caroline Nicolas-Ong, Thérèse Schunck, Malika Schenck, Olivier Collange, Véronique Mutschler, Izzie Jacques Namer, Jean-Louis Dietemann, Chantal Delon-Martin, Francis Schneider

\section{To cite this version:}

Stéphane Kremer, Caroline Nicolas-Ong, Thérèse Schunck, Malika Schenck, Olivier Collange, et al.. Usefulness of functional MRI associated with PET scan and evoked potentials in the evaluation of brain functions after severe brain injury: preliminary results.. Journal de Neuroradiologie / Journal of Neuroradiology, 2010, 37 (3), pp.159-66. 10.1016/j.neurad.2009.07.003 . inserm-00567968

\section{HAL Id: inserm-00567968 https://www.hal.inserm.fr/inserm-00567968}

Submitted on 9 Jun 2011

HAL is a multi-disciplinary open access archive for the deposit and dissemination of scientific research documents, whether they are published or not. The documents may come from teaching and research institutions in France or abroad, or from public or private research centers.
L'archive ouverte pluridisciplinaire HAL, est destinée au dépôt et à la diffusion de documents scientifiques de niveau recherche, publiés ou non, émanant des établissements d'enseignement et de recherche français ou étrangers, des laboratoires publics ou privés. 
USEFULLNESS OF FUNCTIONAL MRI ASSOCIATED WITH PET SCAN AND

EVOKED POTENTIALS IN THE EVALUATION OF BRAIN FUNCTIONS AFTER SEVERE BRAIN INJURY : preliminary results.

INTERET DE L'IRM FONCTIONNELLE ASSOCIEE AU PET SCAN ET AUX POTENTIELS EVOQUES POUR L'EVALUATION DES FONCTIONS CEREBRALES DANS LES ATTEINTES CEREBRALES GRAVES : résultats préliminaires.

Key Words : brain injury, coma, MRI, functional imaging, consciousness, critical care patients

\section{ABSTRACT}

Objective : to evaluate the feasability and the potential usefulness of functional MRI (fMRI) for the evaluation of brain functions after severe brain injury, when compared to a multimodal approach (evoked potentials (EP) and Positron Emission Tomography (PET) examinations)

Material and Methods : 7 patients (mean age: 49 years (23-73), 3 males, 4 females) presenting with coma after acute severe brain injuries underwent functional MRI (auditive, visual, somesthesic), ${ }^{18}$ F-FDG PET and EP (auditive, visual, somesthesic) within a 3-day period of 
time in a mean of 120 days after initial brain injury. fMRI activations in somesthesic, visual and auditive cortical areas were compared to EP (28 possible comparisons) and to the metabolic activity on PET examination in the same anatomical areas (21 possible comparisons).

Results : In case of availability, results were concordant between fMRI and PET in 10 comparisons but not in 1, and between fMRI and EP in 11 comparisons but not in 4 .

Conclusions: In many patients, there is a good concordance between fMRI and brain functions suggested by EP and metabolic activity demonstrated with PET. In few others, fMRI can be integrated in the early evaluation of brain functions to further augment our capacity for a proper evaluation of brain functions in critically ill patients. 
INTRODUCTION :

The prevalence, complexity and multiple medical and socio-economic consequences of severe alterations of brain functions after severe central nervous system injuries, make them a major health challenge. With few exceptions, the pathophysiology and the molecular basis of both acute brain injuries and recovery have yet to be defined, in order to promote proper and efficient treatments. Before that step, the clinical challenge will be to best evaluate injuries because both clinical examination and available tools lack accuracy not only for the diagnosis of damage but also for its prognosis. This is especially true for patients with coma of intermediate severity.

Minimally conscious state (MCS) and vegetative state (VS) are clinically defined as chronic disorders of consciousness. In the vegetative state, patients demonstrate preserved hypothalamic and autonomic functions but are unaware of themselves and of their environment, and are incapable of interaction with others, whereas in the minimally conscious state, patients have limited but discernible evidence of awareness of themselves and of their environment (1).

Different clinical evaluation scales of disorders of consciousness have been developed and help nosological distinction between these entities (2-6). Nevertheless, it remains difficult to evaluate clinically brain functions in many patients (7). If available such information could be of particular clinical interest, as it has been hypothesized that the presence of preserved brain functions could have a prognostic value $(8,9)$. The knowledge of preserved brain 
functions could lead to more efficient rehabilitation planning or to a better adaptation of stimulation treatment $(10,11)$.

Electrophysiological techniques, especially evoked potentials (EP) (visual, auditory and somatosensory) are widely used in this indication (12). Indeed, EP are used in severely brain injured patients to predict clinical outcome, as the absence of residual brain potentials could identify those patients unlikely to recover $(8,13)$. The advantage of the technique is that it is easy to perform at bedside, but its major drawbacks are the frequent presence of environment -related artefacts and a gross localisation information.

Positron Emission Tomography (PET) allows evaluation of cerebral glucose metabolism whereas Single Photon Emission Computed Tomography (SPECT) allows evaluation of cerebral perfusion : They can demonstrate a decrease of global cerebral metabolism and perfusion in persistent vegetative patients. This decrease is more marked in arterial border zones in post-anoxic patients (14-18), and there is a correlation between areas of relatively preserved brain metabolism and residual brain function (18). However, these techniques are not available at bedside everywhere and require either patient transportation or that specialized centers be located close to critical care departments.

More recently functional neuroimaging techniques $\left(\mathrm{H}_{2}{ }^{15} 0\right.$ PET and functional MRI (fMRI)) have been used in clinical research studies to evaluate brain functions in patients presenting chronic disorders of consciousness $(1,19-21)$.

Performed late after the initial injury in comatose patients, these studies have shown that auditory, nociceptive and visual passive stimulations lead to activations of primary cortices 
but also in some cases of secondary associative cortex. The presence of activation in higher order association areas suggests the persistence of integrative processes and may herald better prognosis $(10,20,22-25)$.

Magnetic Resonance Imaging (MRI) provides information about cerebral morphological lesions as well as information about cerebral functions. Morphological MRI is widely used in patients with chronic disorders of consciousness to evaluate brain injuries. fMRI is based on the measurement of signal modifications induced by the variation of deoxyhemoglobin concentration in the cerebral vasculature (BOLD effect) subsequent to cortical activation (26). It can be performed concomitantly with morphological MRI, within a reasonable time duration. This non-invasive technique does not require any contrast agent injection and it provides localization information. Finally, MR scanners are now available in more and more settings. Although there are technical and ethical limitations in the use of fMRI in the evaluation of patients with chronic disorders of consciousness $(23,26)$, it could be interesting to evaluate its contribution to the management of patients with acute severe disorders of consciousness.

The aim of this preliminary work was to evaluate the feasability and the potential usefulness of a fMRI approach, when compared to a multimodal approach (EP and PET examinations) in critical care patients.

\section{MATERIAL AND METHODS :}




\section{PATIENTS :}

After ethical committee approval (Comité de Protection des Personnes, Est-IV, Strasbourg), 7 patients (mean age : 49 years (23-73), 3 males, 4 females) presenting with chronic disorders of consciousness in relation with severe brain injuries (prolonged anoxia following out-ofhospital cardiac arrest : 5 patients, severe head traumatism : 1 patient, intracerebral hemorrhage : 1 patient) were included after informed consent obtained from next of kin.

Patients consciousness was evaluated with the Wessex Head Injury Matrix (WHIM) $(4,25)$ and the presence of susceptibility effects in relation to focal brain haemorrhage was evaluated on T2 GE images in the areas elected for multimodal investigation (parietal, temporal and occipital lobes) (see table 1). Patients were free of centrally acting drugs.

\section{METHODS :}

The different tests (fMRI, PET and EP) were performed in each patient within a 3-day period of time in a range of 120 (12-554) days after initial brain injury.

MRI :

MRI examination was performed on a 1.5 Tesla imager (Avanto, Siemens, Erlangen, Germany) with an 8-channel head coil. Stimuli were presented using a system dedicated to 
fMRI (IFIS-SA, Invivo, Orlando, USA). Patients were equipped with headphones for auditory stimuli delivery while protecting from the scanner's noise. A LCD screen was positioned over the head coil in front of the eyes for visual stimuli presentations. In order to limit patients' movements during the examination, their head was fixed using small cushions. Anatomical images were first acquired using an axial T1 weighted 3D GE imaging (TR $=11 \mathrm{~ms}$, TE $=4.94 \mathrm{~ms}$, Flip angle $=15^{\circ}, 1 \mathrm{~mm}^{3}$ isotropic spatial resolution).

Three fMRI runs were acquired using a classical T2*-weighted EPI GE sequence (TR : 4000 ms, TE : $50 \mathrm{~ms}$, Flip angle : 90 , slice thickness : $4 \mathrm{~mm}$, FOV : $256 \mathrm{~mm}$, matrix : 64x64, 120 volume acquisitions/run) with a whole cortex coverage. For each functional run a different perceptual system (somesthesic, auditive and, when possible, visual) was passively stimulated following a block paradigm design. Block paradigms consisted in 6 alternations of 10 volumes either with or without stimulation.

Somesthesic stimulation consisted in passive tactile mechanical brushing of alternatively right and left legs. Auditive stimulation was performed by the binaural delivery of an $2000 \mathrm{~Hz}$ pure tone pulsed at $1 \mathrm{~Hz}$ through the headphones. When patients had spontaneously their eyes open (4 subjects), visual stimulation was performed through presentation of a $8 \mathrm{~Hz}$ reversing checkerboard on the LCD screen. Stimuli presentation was semi-randomly ordered among patients. 
Functional images were individually processed using SPM2 software (Wellcome Department of Cognitive Neurology, Queen's College, London; http://www.fil.ion.ucl.ac.uk/spm/). The pre processing included a rigid body motion correction, a co registration on the anatomical image using mutual information method, and smoothing by a $8 \mathrm{~mm}$ isotropic Gaussian kernel. Examinations with more than $2 \mathrm{~mm}$ translation or $6^{\circ}$ rotation movements were excluded from further analysis. Individual statistical analyses were performed by solving the linear generalized model in which regressors of interest were modelled by a boxcar function representing the time-course of the stimuli delivery convolved with the canonical hemodynamic response function provided by SPM. Motion parameters were included in the model as regressors of no interest. A high pass filter allowed for the removal of slow drifts in the baseline. Student t-test were computed voxelwise for each stimulus of interest and thresholded at $\mathrm{p}<0.005$ providing a stimulus related activation map. Obtained cortical activation maps were then fused with each patient volumetric T1 anatomical image.

Cortical activation areas of somesthesic, auditive and visual stimulations are well established (27-29). In healthy subjects, somesthesic stimulation of the leg induces activation of primary sensitive cortex situated in the medial part of contralateral postcentral gyrus (Broadman area (BA) : 1, 2 and 3 ). Bilateral auditive stimulation induces activation of bilateral primary auditive cortex situated in Heshl gyrus (BA 41, 42) and secondary auditive cortex situated around of it (BA 22). Bilateral visual stimulation induces activation of bilateral primary visual cortex situated along the calcarine sulcus and in the inferior occipital gyrus (BA 17, 18 and 19). 
When an activated cluster was identified in one of these expected areas, mean time course and percentage of signal change were further derived in regions of interest (ROIs) located in these areas (defined using boxes of $12 \mathrm{~mm}$ width) and visually inspected to either confirm or infirm the activation.

Results of fMRI were considered as normal (1) in case of cortical activation in the expected cortical area with time course of signal modification in accordance with variation of BOLD signal, normal with limitation $\left(1^{*}\right)$ in case of cortical activation in the expected cortical area but without time course of signal modification in accordance with variation of BOLD signal, absent (0), and not interpretable in case of movement artefacts (NI).

PET :

PET measurement was performed on a PET/CT system (Discovery ST, GEMS, Milwaukee, USA) using the most sensitive 3D mode with in-plane and axial resolutions of $3.27 \mathrm{~mm}$. The CT scanner portion of the Discovery ST consists of a 8-detectors helical CT. Imaging parameters were as follows: $140 \mathrm{kVp}, 0 \mathrm{~mA}, 0.8 \mathrm{~s}$ per CT rotation, pitch of $1.675: 1 \mathrm{~mm} / \mathrm{s}$ table speed.

Patients were injected intravenously $150 \mathrm{MBq}{ }^{18} \mathrm{~F}-\mathrm{FDG}$ at a resting state in a dimly lighted room with minimal background noise. Data acquisition was started 30 min after injection. 
Scan duration was 15 min. PET images were reconstructed using CT for attenuation correction with the OSEM algorithm.

PET images were analysed by two readers (CNO, IJN) after coregistration of PET color maps with the 3DT1 (3D Siemens software), in the different functional areas (temporal, occipital and parietal) and cortical fixation was classified as normal (1), hypofixation (0), in case of diminished fixation, or not interpretable (NI) in case of movement artefacts.

\section{EVOKED POTENTIALS :}

Patients were tested for 3-modality exogenous evoked potentials (EPs), including visual (VEP), somatosensory EPs (SEP) and event related potentials (ERPs) during a classic auditory oddball paradigm. EPs were recorded with a Nihon Kohden Neuropack8 apparatus (Japan), using standard techniques. All recordings were performed twice to check waveform reproducibility.

SEPs were obtained after average of the response to 200 median nerve electrical stimulations at the wrist with recording sites at Erb's point (to ensure peripheral passage) and above controlateral parietal region. Waves analysis was expressed in terms of presence, deterioration or absence of primary cortical response N20.

VEPs were generated by averaging the responses to 100 reversals of red-light emitting diodes (goggles) presented separately to each eye at a $0.9 \mathrm{~Hz}$ frequency, on the recording site located 
at the median occipital electrode $\mathrm{Oz}$ (reference $\mathrm{Cz}$ ). Wave analysis was expressed in terms of presence, deterioration or absence of occipital primary response.

ERPs were recorded using an auditory oddball paradigm in passive conditions. Deviant (2000 $\mathrm{Hz}$ tones; probability of occurrence $=0.20)$ and standard stimuli $(1000 \mathrm{~Hz}$ tones; probability of occurrence $=0.80$ ) were presented binaurally at random with a level of $90 \mathrm{~dB}$. About 50 deviant stimuli were required for each sequence. Responses were recorded with middle frontal Fz-, central Cz- and parietal Pz- electrodes referred to linked earlobes on a 1 sec-base duration of time. Ocular movements or blinking during the session required manually holding of the eyes to decrease artefacts. Wave analysis focused on the presence, the deterioration or the absence of auditory cortical response N100 which corresponds to primary/secondary auditory cortex, as well as of P300 which corresponds to the involvement of more cognitive functions (positive peak occurring in a latency range of $250-600 \mathrm{msec}$ in response to deviant stimuli). Evoked potentials were analysed as normal (1), altered $\left(1^{*}\right)$ in case of deterioration of waves, absent (0) or not interpretable in case of movement artefacts (NI).

EVALUATION OF CONCORDANCE BETWEEN fMRI RESULTS, PET AND EP RESULTS:

The results of fMRI activations in somesthesic, visual and auditive cortical areas were compared to the results of EP and to the presence/absence of a normal metabolic activity on 
PET examination in the same anatomical areas. They were considered as concordant in case of similar results in the same cortical area between fMRI and another examination, non concordant in case of discrepancies between fMRI and another examination or not possible if a result was missing. Because EP have no localizing value (the integrity of one cortical area gives a normal result), we considered as concordant unilateral or bilateral cortical activation observed on fMRI. It was also difficult to distinguish primary and secondary auditive cortex on PET metabolic maps because of poor spatial resolution. This is why we considered as normal the presence of any cortical activation in the auditory cortex (primary or secondary) and compared it to the global metabolic activity in the temporal area.

\section{RESULTS:}

Results are presented in Table 2 for our seven patients. Concordances / discordances are recorded as colored boxes in the legend of table 2.

FUNCTIONAL MRI :

fMRI was not interpretable in 4 data-points (patient 6) because of important motion- related artefacts. fMRI was not available in 3 data-points (patients 1,5 and 7), because the patient closed spontaneously their eyes during the examination and this did not allow for visual stimulation. 
In 5 data-points, the interpretation was limited because of cortical activation in the expected cortical area but without time course of signal modification in accordance with a variation of the BOLD signal.

In seven regions of multimodal analysis (patients 2,6 and 7) there were susceptibility artefacts observed in relation to cerebral hemorrhage. Among these regions, 4 did not present fMRI activations.

\section{EVOKED POTENTIALS :}

EP were not available in one data-point (patient $5:$ SEP) and not interpretable in 5 datapoints.

PET :

PET was not interpretable in 3 data-points (patient 4) because anesthesia became mandatory during the examination. 
Concordance between fMRI and PET:

PET results were not interpretable in patient 4, and fMRI results were not either available or interpretable in 7 data-points. This did not allow for comparison of fMRI and PET results in these 11 data-points.

Results were concordant between fMRI and PET in 10 data-points and discordant in 1 datapoint.

Concordance between fMRI and evoked potentials:

EP were not either available in one data-point (patient 5 : SEP) or interpretable in 5 datapoints, and fMRI results were not available or not interpretable in 7 data-points. This did not allow comparison of fMRI and EP results in 13 cases.
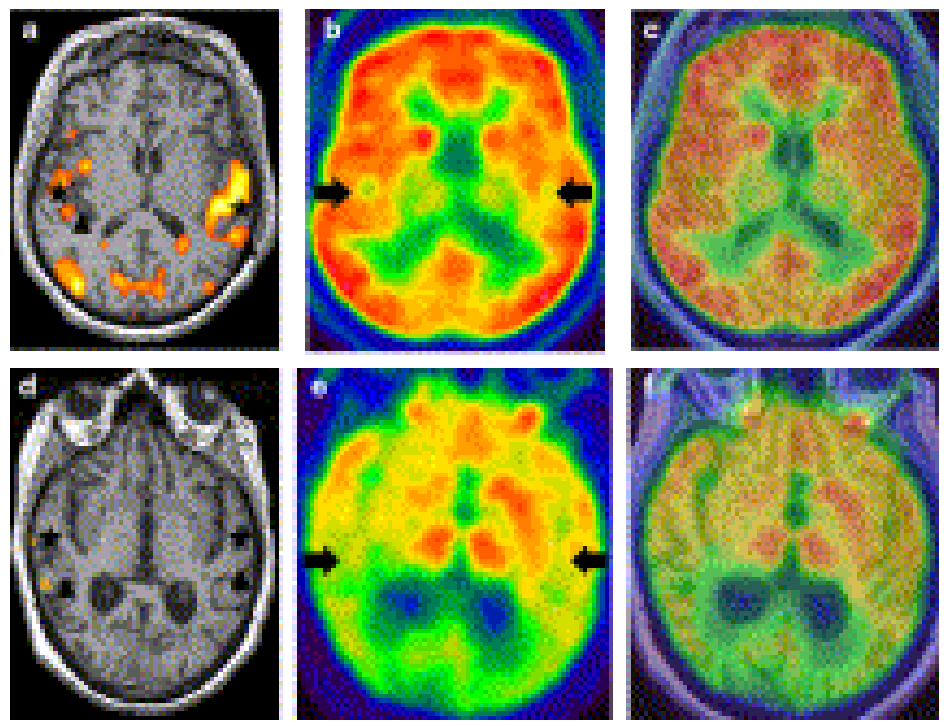
Results were concordant between fMRI and EP in 11 data-points and discordant in 4.

Figure 1 displays a concordant pattern of responses (patient \#1, upper row) and a discordant pattern of responses (patient \#3, lower row).

\section{DISCUSSION}

Our results show in many patients a concordance between fMRI and brain functions suggested by EP and resting metabolic activity demonstrated with PET. Moreover, this study demonstrates the feasibility of fMRI in critical care patients, as the number of examinations that are not interpretable is not higher with fMRI (6 data-points), than with either PET (3 datapoints) or EP (6 data-points).

The usefulness of EP and PET scan in the evaluation of brain functions and cerebral metabolism in chronic disorders of consciousness and their potential prognostic value have already been proposed in the literature $(20,21,30-32)$. But, although number of recently published studies have evaluated fMRI in this indication, using nociceptive, auditive, visual or more elaborated stimulations $(7,10,20,30,31,33-40)$, its usefullness as a clinically "easy to perform" examination combining multiple stimulations in association to these gold standards has never been done before in the setting of severe brain injuries. Moreover, our study was prospective, in consecutive non-selected patients, conditions that sometimes lead to the conclusion that a newly available technique should be restricted to specific patients. We report that even in variable and sometimes short period of time between cerebral injury and 
testing, fMRI evaluation can afford to bring information on remaining brain functioning that is not accessible to clinical evaluation. Although we did not perform all the fMRI in the same range of time after initial damage, this must not be considered as a pitfall of the study, but should rather indicate that this examination has not necessarily to be done as late as in previous studies $(31,34,38,40)$.

Discordances between fMRI and EP or PET, particularly the absence of fMRI activation in case of normal metabolic cortical activity or normal EP could be related to a different hemodynamic response in comatose patients, when compared to normal subjects, or to the presence of cortical susceptibility effects induced by the presence of hemorrhage.

Our fMRI results can be separated into 3 types : normal cortical activation as compared to those of healthy volunteers, absence of cortical activation, and a group of intermediate results with difficult interpretation because of cortical activation in the expected cortical area but without time course of signal modification in accordance with variation of BOLD signal. In such cases, results need comparison to clinical data, but also to EP and cortical metabolism as evaluated with PET. The discordances between the observed cortical activations and the absence of signal time course modification in relation to the variation of BOLD signal point out one of the main limit of fMRI technique in chronic disorders of consciousness. Indeed the BOLD response is supposed to be based on a normal neurovascular coupling between neuronal activation and local hemodynamics (41). Vegetative state patients' cortical hemodynamic response could be different, when compared to normal subjects, and could induce aberrant cortical activations $(23,26)$. The other limitation of functional MRI is the 
presence of cortical susceptibility effects, in relation to the presence of cerebral hemorrhage, which could dramatically alter BOLD images. In seven regions of multimodal analysis (patients 2,6 and 7) there were susceptibility artefacts observed in relation to cerebral hemorrhage. Among these regions, 4 did not present fMRI activations.

The realisation and interpretation of fMRI requires a perfect immobility of the patients (patient 6), but also the absence of centrally acting drugs. This is also the case for PET and EP which are not always easy to perform or to interpret in patients with chronic disorders of consciousness, particularly when anesthesia or analgesia are required (patient 4) for PET or when motion artefacts or electrical interferences occur during the performance of evoked potentials at bedside.

Our data suggest that the evaluation of brain functions after severe brain injury would benefit of fMRI because this technique can sometimes compensate for the pitfalls of evoked potentials or PET as indicated in patient 1, in whom auditive and somesthesic EP were not interpretable. Moreover the discordant comparisons between fMRI and PET or fMRI and evoked potentials, are also associated to discordant results between PET and EP (patient 3: vision and auditive). This illustrates the difficulties of evaluation of brain functions in some brain injured patients only with EP and PET: a multimodal approach associating PET, evoked potential and fMRI could therefore be of interest for physicians, patients and even families who desperately expect even tiny information on prognosis .

However, MRI is easy to realise, non invasive and supplies in the same time information about morphological brain lesions induced by a trauma or anoxia; moreover, it brings 
information about brain functions like cortical integration of vision, of audition and of sensitivity. As compared to EP, functional MRI gives a direct visualisation of cortical activation, with good anatomical localisation in both cerebral hemispheres.

This information has very important clinical implications since preserved brain functions have a prognostic value (8-10). Indeed knowledge of preserved brain functions could lead to different rehabilitation planning with a better adaptation of stimulation treatment $(11,12)$. For example, patient 1 had no visual response but some auditory integration response; therefore clinical rehabilitation was axed on auditory stimulation. These data are important for the medical staff in charge of the patients.

In conclusion, fMRI increases the accuracy of neurological evaluation in our series of critically ill patients with acute brain injury, provided that the BOLD signal can be properly interpreted. It turns out, to be an additional tool of interest to complete evaluation in those patients where EP and PET examinations are discordant. In addition it may help physicians to evaluate with more certainty severe residual neurological impairment and progress in ethical choices if a real prognostic value can be observed among large cohorts of patients. 


\section{REFERENCES}

1. Bernat JL. Chronic disorders of consciousness. Lancet 2006;367(9517):1181-1192.

2. Giacino JT. The vegetative and minimally conscious states: consensus-based criteria for establishing diagnosis and prognosis. NeuroRehabilitation 2004;19(4):293-298.

3. Giacino JT, Ashwal S, Childs N, et al. The minimally conscious state: definition and diagnostic criteria. Neurology 2002;58(3):349-353.

4. Majerus S, Gill-Thwaites H, Andrews K, et al. Behavioral evaluation of consciousness in severe brain damage. Prog Brain Res 2005;150:397-413.

5. Teasdale G, Jennett B. Assessment of coma and impaired consciousness. A practical scale. Lancet 1974;2(7872):81-84.

6. Wijdicks EF, Bamlet WR, Maramattom BV, et al. Validation of a new coma scale: The FOUR score. Ann Neurol 2005;58(4):585-593.

7. Bernat JL. Can functional MRI detect awareness when a neurological examination does not? Nat Clin Pract Neurol 2007;3(9):490-491.

8. Hildebrandt H, Happe S, Deutschmann A, et al. Brain perfusion and VEP reactivity in occipital and parietal areas are associated to recovery from hypoxic vegetative state. J Neurol Sci 2007;260(1-2):150-158. 
9. Naccache L, Puybasset L, Gaillard R, et al. Auditory mismatch negativity is a good predictor of awakening in comatose patients: a fast and reliable procedure. Clin Neurophysiol 2005;116(4):988-989.

10. Giacino JT, Hirsch J, Schiff N, et al. Functional neuroimaging applications for assessment and rehabilitation planning in patients with disorders of consciousness. Arch Phys Med Rehabil 2006;87(12 Suppl 2):S67-76.

11. Laureys S, Giacino JT, Schiff ND, et al. How should functional imaging of patients with disorders of consciousness contribute to their clinical rehabilitation needs? Curr Opin Neurol 2006;19(6):520-527.

12. Lew HL, Poole JH, Castaneda A, et al. Prognostic value of evoked and event-related potentials in moderate to severe brain injury. J Head Trauma Rehabil 2006;21(4):350-360.

13. Rothstein TL. The role of evoked potentials in anoxic-ischemic coma and severe brain trauma. J Clin Neurophysiol 2000;17(5):486-497.

14. Beuthien-Baumann B, Handrick W, Schmidt T, et al. Persistent vegetative state: evaluation of brain metabolism and brain perfusion with PET and SPECT. Nucl Med Commun 2003;24(6):643-649.

15. De Volder AG, Michel C, Guerit JM, et al. Brain glucose metabolism in postanoxic syndrome due to cardiac arrest. Acta Neurol Belg 1994;94(3):183-189.

16. Laureys $\mathrm{S}$, Lemaire $\mathrm{C}$, Maquet $\mathrm{P}$, et al. Cerebral metabolism during vegetative state and after recovery to consciousness. J Neurol Neurosurg Psychiatry 1999;67(1):121. 
17. Rudolf J, Ghaemi M, Ghaemi M, et al. Cerebral glucose metabolism in acute and persistent vegetative state. J Neurosurg Anesthesiol 1999;11(1):17-24.

18. Schiff ND, Ribary U, Moreno DR, et al. Residual cerebral activity and behavioural fragments can remain in the persistently vegetative brain. Brain 2002;125(Pt 6):1210-1234. 19. Laureys S. Functional neuroimaging in the vegetative state. NeuroRehabilitation 2004;19(4):335-341.

20. Laureys S, Owen AM, Schiff ND. Brain function in coma, vegetative state, and related disorders. Lancet Neurol 2004;3(9):537-546.

21. Schiff ND. Multimodal neuroimaging approaches to disorders of consciousness. J Head Trauma Rehabil 2006;21(5):388-397.

22. Boly M, Faymonville ME, Peigneux $\mathrm{P}$, et al. Auditory processing in severely brain injured patients: differences between the minimally conscious state and the persistent vegetative state. Arch Neurol 2004;61(2):233-238.

23. Kobylarz EJ, Schiff ND. Functional imaging of severely brain-injured patients: progress, challenges, and limitations. Arch Neurol 2004;61(9):1357-1360.

24. Laureys S, Faymonville ME, Degueldre C, et al. Auditory processing in the vegetative state. Brain 2000;123 ( Pt 8):1589-1601.

25. Laureys S, Faymonville ME, Peigneux P, et al. Cortical processing of noxious somatosensory stimuli in the persistent vegetative state. Neuroimage 2002;17(2):732-741. 26. Ogawa S, Lee TM, Kay AR, et al. Brain magnetic resonance imaging with contrast dependent on blood oxygenation. Proc Natl Acad Sci U S A 1990;87(24):9868-9872. 
27. Miki A, Liu GT, Modestino EJ, et al. Functional magnetic resonance imaging of the visual system. Curr Opin Ophthalmol 2001;12(6):423-431.

28. Penfield W, Jasper H. Epilepsy and functional anatomy of the human brain. Boston: Little, Brown; 1959.

29. Wessinger CM, VanMeter J, Tian B, et al. Hierarchical organization of the human auditory cortex revealed by functional magnetic resonance imaging. J Cogn Neurosci 2001;13 (1):1-7.

30. Laureys S, Piret S, Ledoux D. Quantifying consciousness. Lancet Neurol 2005;4(12): 789-790.

31. Owen AM, Coleman MR, Boly M, et al. Detecting awareness in the vegetative state. Science 2006;313(5792):1402.

32. Schiff ND, Fins JJ. Disorders of consciousness. Mayo Clin Proc 2007;82(2):250-251; author reply 251 .

33. Boly M, Coleman MR, Davis MH, et al. When thoughts become action: an fMRI paradigm to study volitional brain activity in non-communicative brain injured patients. Neuroimage 2007;36(3):979-992.

34. Coleman MR, Rodd JM, Davis MH, et al. Do vegetative patients retain aspects of language comprehension? Evidence from fMRI. Brain 2007;130(Pt 10):2494-2507.

35. Di HB, Yu SM, Weng XC, et al. Cerebral response to patient's own name in the vegetative and minimally conscious states. Neurology 2007;68(12):895-899. 
36. Metting Z, Rodiger LA, De Keyser J, et al. Structural and functional neuroimaging in mild-to-moderate head injury. Lancet Neurol 2007;6(8):699-710.

37. Owen AM, Coleman MR, Boly M, et al. Using functional magnetic resonance imaging to detect covert awareness in the vegetative state. Arch Neurol 2007;64(8):1098-1102.

38. Owen AM, Coleman MR, Menon DK, et al. Residual auditory function in persistent vegetative state: a combined PET and fMRI study. Neuropsychol Rehabil 2005;15(3-4):290306.

39. Perrin F, Schnakers C, Schabus M, et al. Brain response to one's own name in vegetative state, minimally conscious state, and locked-in syndrome. Arch Neurol 2006;63(4): 562-569.

40. Schiff ND, Rodriguez-Moreno D, Kamal A, et al. fMRI reveals large-scale network activation in minimally conscious patients. Neurology 2005;64(3):514-523.

41. Seiyama A, Seki J, Tanabe HC, et al. Circulatory basis of fMRI signals: relationship between changes in the hemodynamic parameters and BOLD signal intensity. Neuroimage 2004;21(4):1204-1214.

FIGURE LEGEND 
Figure 1 : Patient 1 : Figure 1a (Auditive Functional MRI), 1b ( ${ }^{18} \mathrm{~F}-\mathrm{FDG}$ PET scan), 1c (coregistration of PET color maps with the 3DT1): concordant results, with bilateral activation of primary (star) and secondary auditory areas (arrow head) on functional MRI and bilateral normal temporal metabolism on PET scan (arrow). Patient 3 : Figure 1d (Auditive Functional MRI), 1e ( ${ }^{18} \mathrm{~F}-\mathrm{FDG}$ PET scan), 1f (coregistration of PET color maps with the 3DT1) : discordant results, with limited activation of primary (star) and secondary auditory cortex (arrow head) on the right side and no activation on the left side, and normal temporal metabolism on the left side, but hypometabolism on the right side on PET scan (arrow). 


\section{TABLES :}

\begin{tabular}{|c|c|c|c|c|c|c|c|}
\hline & Patient 1 & Patient 2 & Patient 3 & Patient 4 & Patient 5 & Patient 6 & Patient 7 \\
\hline Age (years) & 35 & 63 & 67 & 33 & 73 & 52 & 23 \\
\hline Etiology & $\mathrm{CA}$ & $\mathrm{CA}$ & $\mathrm{CA}$ & $\mathrm{CA}$ & $\mathrm{CA}$ & HT & $\mathrm{IH}$ \\
\hline $\begin{array}{l}\text { Clinical } \\
\text { evaluation } \\
\text { consciousness }\end{array}$ & VS & MCS & MCS & MCS & VS & VS & VS \\
\hline WHIM & 0 & 27 & 21 & 22 & 0 & 7 & 2 \\
\hline Time (days) & 12 & 32 & 143 & 14 & 20 & 554 & 68 \\
\hline $\begin{array}{l}\text { Cerebral } \\
\text { hemorrhage }\end{array}$ & no & $\begin{array}{l}\text { Yes : right and } \\
\text { left occipital } \\
\text { lobe, left } \\
\text { parietal lobe }\end{array}$ & no & no & no & $\begin{array}{l}\text { Yes : left } \\
\text { temporal and } \\
\text { parietal lobe }\end{array}$ & $\begin{array}{l}\text { Yes : right } \\
\text { temporal and } \\
\text { occipital lobe }\end{array}$ \\
\hline
\end{tabular}

Table 1 : Patients clinical and radiological characteristics.

CA : Cardiac Arrest, HT : Head Traumatism, IH : Intracerebral Hemorrhage, MCS :

Minimally Conscious State, VS : Vegetative State, Time: Time from acute injury to test performance (in days), cerebral hemorrhage : presence of susceptibility effects in relation to intracerebral hemorrhage on $\mathrm{T} 2 \mathrm{GE}$ sequence. 


\begin{tabular}{|c|c|c|c|c|c|c|c|c|}
\hline \multicolumn{2}{|c|}{ Patients } & 1 & 2 & 3 & 4 & 5 & 6 & 7 \\
\hline \multirow{3}{*}{$\begin{array}{c}\text { Somatosensor } \\
\mathrm{y}\end{array}$} & PET (R/L) & $0 / 0$ & $1 / 0$ & $0 / 0$ & $\mathrm{NI}$ & $0 / 0$ & $1 / 1$ & $0 / 1$ \\
\hline & SEP & NI & 1 & NI & 1 & NA & 1 & 1 \\
\hline & fMRI (R/L) & $0 / 0$ & $1 / 0$ & $0 / 0$ & $0 / 0$ & $0 / 0$ & NI & $0 / 1$ \\
\hline \multirow[t]{3}{*}{ Visual } & PET (R/L) & $0 / 0$ & $1 / 0$ & $0 / 0$ & $\mathrm{NI}$ & $1 / 1$ & $1 / 0$ & $0 / 1$ \\
\hline & VEP & $1 *$ & $1^{*}$ & 1 & $1 *$ & 0 & $1^{*}$ & $1 *$ \\
\hline & fMRI (R/L) & $\mathrm{NA}$ & $1 / 0$ & $0 / 0$ & $1 * / 1 *$ & NA & $\mathrm{NI}$ & NA \\
\hline \multirow[t]{5}{*}{ Auditive } & PET (R/L) & $1 / 1$ & $1 / 0$ & $0 / 1$ & NI & $0 / 0$ & $1 / 0$ & $0 / 1$ \\
\hline & N100 & NI & 1 & 1 & 1 & 0 & 1 & 1 \\
\hline & $\begin{array}{c}\text { fMRI I } \\
(\mathrm{R} / \mathrm{L})\end{array}$ & $1 / 1$ & $1 / 1$ & $1 * / 0$ & $0 / 0$ & $0 / 0$ & NI & $1 / 1$ \\
\hline & P300 & NI & $\mathrm{NI}$ & 0 & 0 & 0 & 1 & 1 \\
\hline & $\begin{array}{c}\text { fMRI II } \\
(\mathrm{R} / \mathrm{L})\end{array}$ & $1 / 1$ & $1 / 1 *$ & $1 * / 0$ & $0 / 0$ & $0 / 0$ & NI & $1 / 1$ \\
\hline
\end{tabular}

Table 2 : Synthesis of results :

NA : not available. PET : $0=$ hypofixation, $1=$ normal, NI= not interpretable. Evoked potentials : SEP : somatosensory evoked potentials, VEP : visual evoked potentials, $1=$ normal, $1^{*}=$ altered, $0=$ absent, NI : not interpretable. fMRI : functional MRI, fMRI I : primary auditive area, fMRI II : secondary auditive area, $1=$ normal, $0=$ Absent, $1 *=$ normal with limitation. 
Green boxes correspond to concordant results, the light red ones to discordant and blue boxes mean that no comparison was possible because of missing results.

Conflict of interest : None 